\title{
The pre-anesthetic evaluation for ophthalmic surgery in the elderly is really necessary? The reality of a public hospital
}

\author{
A avaliação pré-anestésica para cirurgia oftalmológica \\ em idosos é realmente necessária? \\ $A$ realidade de um hospital público
}

Flora Margarida Barra Bisinotto', Gustavo Borges Mesquita², Adriana Nazaré Miziara³, Laura Bisinotto Martins ${ }^{4}$, Gustavo Olivieri Barcellos ${ }^{5}$, Luciano Alves Matias da Silveira ${ }^{6}$

\begin{abstract}
Objectives - Pre-anesthetic assessment (PAA) and laboratory tests are questioned for ophthalmic procedures due to their additional costs and surgery delays. These are lower risks, nonetheless, patients are elderly and suffer from multiple comorbidities. The aim of this study was to determinate if it is really necessary in a public hospital. Method - a retrospective study on 297 medical records containing the pre-anesthetic questionary from ophthalmic surgery patients in a public hospital was leaded. By the anamnesis, clinical examination and laboratory tests, the rate of patients who came up with unknown or uncontrolled diseases for the pre-anesthetic evaluation among with unsettled lab tests were analyzed. Results - The patients's mean age was 71.5 years old. $95.28 \%$ of them suffer from at least one chronic disease. The most prevailer illness was systemic arterial hypertension (SAH) $(62.96 \%)$, which in $7.7 \%$ of were uncontroled. Also $2.3 \%$ had no diagnosis of SAH. The DM2 appeared in second (22.22\%), with $5.3 \%$ without proper management. Glycaemia above $100 \mathrm{mg} . \mathrm{dl}$ ${ }^{1}$ was found in $25.92 \%$, undiagnosed; $84.8 \%$ of the total were taking at least one medication. Only $73.4 \%$ of patients were released for surgery in the first moment. Discussion - To sum up, PAA in ophthalmology surgery is able to bring up undiagnosed diseases, or unstable medical conditions, and it plays a role not only in optimize the patient for surgery, but also as primary care. It can be an important deal to improve population's health, therefore, considered necessary in elderly patients in the public health system.
\end{abstract}

Keywords: Pre-anesthetic assessments; Anaesthesia; Ambulatory anaesthesia; Cataract extraction; Aged

\footnotetext{
1 Surgery Department, Universidade Federal do Triângulo Mineiro, Uberaba, MG, Brazil.

${ }^{2}$ Medical Residency Program in Anesthesiology, Centro de Ensino e Treinamento, Hospital de Clínicas, Universidade Federal do Triângulo Mineiro, Uberaba, MG, Brazil

${ }^{3}$ Department of Internal Medicine, Universidade Federal do Triângulo Mineiro, Uberaba, MG - Brazil.

${ }^{4}$ Scientific Initiation Program, Universidade Federal do Triângulo Mineiro, Uberaba, MG, Brazil; Medicine Academic Course, Universidade de Ribeirão Preto - Ribeirão Preto, SP, Brazil.

${ }^{5}$ Scientific Initiation Program, Universidade Federal do Triângulo Mineiro, Uberaba, MG, Brazil; Medicine Academic Course, Universidade Federal do Triângulo Mineiro - Uberaba, MG, Brazil.

${ }^{6}$ Department of Surgery, Universidade Federal do Triângulo Mineiro, Uberaba, MG, Brazil.
}

Study carried out at Hospital de Clínicas of Universidade Federal do Triângulo Mineiro - UFTM.

The authors declare no conflicts of interests.

Received for publication 08/05/2016 - Accepted for publication 20/06/2016. 


\section{RESUMO}

Objetivos:A avaliação pré-anestésica (APA) e a realização de exames laboratoriais são questionadas para cirurgias oftalmológicas ambulatoriais por acrescentarem custos e retardarem a cirurgia. Estas são de baixo risco, mas os pacientes são idosos e com várias comorbidades. O objetivo deste estudo foi determinar se a APA é realmente necessária nestes pacientes em um hospital público. Métodos: Foi conduzido um estudo retrospectivo em 297 prontuários contendo a APA de pacientes para cirurgias oftalmológicas em um hospital público. Foram avaliados através da história, exame clínico e exames complementares, a proporção de pacientes que apresentaram na APA doenças desconhecidas ou não controladas e alterações dos exames complementares. Resultados: A média de idade dos pacientes foi de 71,5 anos, com 95,28\% tendo pelo menos uma doença crônica. A doença mais prevalente foi hipertensão arterial sistêmica (62,96\%), que em 7,7\% dos pacientes estavam sem controle adequado; $2.3 \%$ não tinham diagnóstico de HAS. O diabetes mellitus tipo 2 apareceu em segundo (22,22\%), com 5,3\% sem controle adequado. Glicemia acima de 100 mg.dl ${ }^{-1}$ foi encontrada em 25,92\%, sem diagnóstico conhecido. Do total, 84,8\% tomavam pelo menos um medicamento. Somente $73,4 \%$ dos pacientes foram liberados para a cirurgia na primeira consulta. Conclusão: A APA em oftalmologia é capaz de detectar doenças não diagnosticadas, ou condições clínicas instáveis, e exerce um papel não só de otimização do paciente para a cirurgia como de atendimento primário, desempenhando papel importante na saúde global da população e, portanto, considerada necessária nos pacientes idosos do sistema público de saúde.

Descritores: Avaliação pré-anestésica; Anestesia; Anestesia ambulatorial; Extração de catarata; Idoso

\section{INTRODUCTION}

$\mathbf{P}$ atients scheduled for surgery with anesthesia have their preoperative evaluation and request for complementary tests $^{1}$ performed by the surgeon who then refers the patients for pre-anesthetic assessment (PAA). This is part of perioperative care for elective surgeries, and has been performed by the Anesthesiology Service of the Hospital de Clínicas of Universidade Federal do Triângulo Mineiro (HC-UFTM) since 2005, following a model already consolidated ${ }^{2}$. Among the various specialties, ophthalmology has large surgical volume. With the already high number and forecast future growth, it is essential to be able to improve safety, as well as the efficiency in both the effectiveness of the surgery as in the costs of these procedures. The elimination of extensive preoperative tests, as well as doctor's appointments, represent a promising area of savings in the health system, besides avoiding delays in the surgical process and does not represent a cause of suspensions-5. On an ambulatory basis, most of these surgeries are performed and, for them to be safe and get good results, careful patient selection is crucial. However, there is some uncertainty among anesthesiologists regarding the suitability of certain patients for some ambulatory surgeries. Since these are considered low-risk surgeries, there are no clear guidelines if a pre-anesthetic evaluation should be performed, as well as the time that it should be done $e^{6-9}$. Studies show different approaches to the selection of outpatients as well as the model for the realization of the PAA, the need for interdisciplinary assessments and complementary examinations ${ }^{10-16}$. Most surgeries are cataract correction, in predominantly elderly patients, and with a high prevalence of systemic comorbidities related to age.

This study aimed to assess whether the PAA model for eye surgery, performed by the Anesthesiology Service from the Hospital de Clínicas of UFTM is really necessary, by analyzing the percentage of patients with well known diseases, but not clinically controlled; PAA's ability to diagnose new diseases, hitherto unknown by patients; and to detect changes in additional tests.

\section{MethodS}

After approval of CEP from UFTM, according to Resolution 466 from December 12, 2012, we conducted a retrospective cross-sectional exploratory study of patient records of an ambulatory unit of UFTM who underwent preanesthetic evaluation consultation for eye surgery in the years 2014 and 2015. All patients initially went through a consultation with the eye doctor, that after indicating the surgery, performed the requests of preoperative tests as routine procedure of the specialty, and would refer the outpatient pre-anesthetic consultation with the anesthesiologist. The research began with the making a list of patients seen at the Ophthalmology Service that had been referred to the pre-anesthetic evaluation, after being scheduled for cataract correction, glaucoma, retina, transplantation and oculoplasty surgery. A demographic analysis was performed considering demographic aspects and health conditions. Inclusion criteria were the records of adult patients aged greater than or equal to 60 years that had gone through the pre-anesthetic consultation, and the excluded were those records that did not contain the pre-anesthetic evaluation form attached. After the addition, data were collected from the review of the records of consultations, attached to medical records, as already described. We evaluated the demographic and clinical aspects obtained from medical history, physical examination and additional tests. To differentiate the presence of pre-existing diseases, but without proper control, from those diagnosed in the pre-anesthetic evaluation, a review of medical records was made.

Medical changes were classified according to the medical field that had change: cardiology, pulmonology, neurology, gastroenterology, hematology or oncology, dermatology, nephrology and endocrinology.

The record of the medications used by patients was made and, finally, the number of consultations in the PAE until the final release of the patient for ophthalmic surgery.

\section{Statistical analysis}

A database was organized in Excel ${ }^{\circledR} 2010$, and implemented for statistical analysis in SPSS version 17.0. The descriptive statistical analysis was used, using for numerical variables, central tendency and dispersion measures, and for the categorical variables, absolute and relative frequencies 
The following factors behavior was considered to conclude the analysis of the need of the current pre-anesthetic evaluation model, and the pre-anesthetic appointment before eye surgery: comorbidity, number of medications, blood pressure measurements, results of additional tests (glucose, urea, creatinine, chest $\mathrm{x}$-ray and electrocardiogram) and the ASA classification. To indicate the need for pre-anesthetic evaluation it was deemed necessary a behavior different from normal for one or more variables from that set.

Table 1

Clinical and demographic characteristics of study participants

\begin{tabular}{lc}
\hline Characteristics & N (\%) \\
\hline Age & \\
60-75 years old & $205(69.0)$ \\
$76-85$ years old & $82(27.6)$ \\
$\geq 86$ years old & $10(3.4)$ \\
Gender & \\
Male & $146(49.2)$ \\
Female & $151(50.8)$ \\
Surgery type & \\
Cataract & $257(86.5)$ \\
Retinous & $16(5.4)$ \\
Oculoplasty & $15(5.1)$ \\
Glaucoma & $6(2.0)$ \\
Others & $3(1.0)$ \\
Comorbidties & \\
Cardiac diseases & $229(77.1)$ \\
Endocrine diseases & $98(32.9)$ \\
Pulmonary diseases & $51(17.1)$ \\
Others diseases & $44(14.8)$ \\
ASA classification & \\
1 & $10(3.3)$ \\
2 & $209(70.3)$ \\
3 & $74(24.9)$ \\
4 & $4(1.3)$ \\
\hline
\end{tabular}

\section{RESULTS}

519 records were reviewed, following a list of patients scheduled for ophthalmic surgery, but only 297 (57,22\%) of them were included in the study because they had pre-anesthetic evaluation form attached. $222(42,78 \%)$ remaining did not contain the evaluation form, which can be justified by a lack of routine from the eye surgeons in referring all patients for pre-anesthetic consultation.

The main demographic and clinical characteristics of patients can be seen in Table 1 . The average age was 71.5 years. Most patients had cataract correction surgery as the primary indication for surgery $(86,5 \%)$, followed by retinal diseases $(5,4 \%)$, oculoplasty $(5,1 \%)$, glaucoma $(2,0 \%)$ and other rare surgery $(1,0 \%)$, such as procedures on the cornea and tear duct. In the assessment of comorbidities, there was a report of at least one disease in $95,28 \%$ of patients, and $77,10 \%$ of them reported the presence of heart disease, whose diagnoses were mainly systemic hypertension, in $62,96 \%$, and coronary artery disease, arrhythmias, or Chagas disease in others. Endocrine diseases emerged as the second most prevalent $(32,9 \%)$, the main one being diabetes mellitus type $2(22,22 \%)$, followed by hypothyroidism $(10,77 \%)$. Lung diseases were the third most prevalent pathology $(17,1 \%)$, and included smoking and chronic obstructive pulmonary disease (COPD). Other less common diseases such as neurological diseases (stroke, epilepsy, Parkinson's and Alzheimer's disease) and kidney disease, such as chronic renal failure (CRF), totaled $14,8 \%$.

When abnormal data obtained from physical examination or abnormal results of laboratory tests were analyzed, these were mainly in relation to the measurement of blood pressure (BP), which was high in 24 patients $(8,0 \%)$, and 17 patients already had previous diagnosis of hypertension and 7 patients $(2,3 \%)$ were unaware of the disease.

Additional tests routinely ordered by the surgeon are blood test, urea dosage, creatinine, sodium, potassium and fasting glucose, bleeding time and coagulation, electrocardiogram (ECG) and chest X-ray. Altered results were mainly the dosage of glucose, urea, creatinine, ECG report and chest X-ray.

Of the total, $153(51,85 \%)$ had no history of diabetes mellitus and had fasting blood glucose levels lower than 100 mg.dl-1 ${ }^{-1}$ In 144 patients $(48,48 \%$ of the total) the results of the fasting blood glucose was above $100 \mathrm{mg}^{\mathrm{dl}} \mathrm{l}^{-1}$, and $50(16,83 \%$ of the total) were known to be carriers of type $2 \mathrm{DM}$ and had blood glucose lower than $180 \mathrm{mg}^{-\mathrm{dl}^{-1}}$. But 16 patients $(5,38 \%$ of the total) were also diagnosed with type $2 \mathrm{DM}$ with the glucose above $180 \mathrm{mg} \cdot \mathrm{dl}^{-1}$. Seventy eight patients $(25,92 \%$ of the total) reported they do not have DM, but presented the results of blood glucose higher than or equal to $100 \mathrm{mg}^{\mathrm{dl}} \mathrm{l}^{-1}$. (Figure 1).

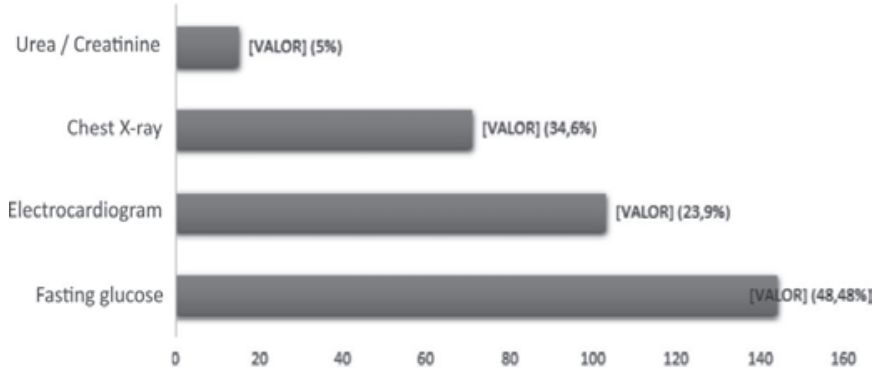

Figure 1: Number (percentage) of abnormal results obtained from the analysis of 297 patient records.

A changing in the dosage of urea and creatinine was present in 15 patients $(5 \%)$. (Figure 1$)$.

On ECG were found changes such as ischemia, arrhythmias, blockage of branches and atrial and ventricular hypertrophy in 103 patients $(34,68 \%)$. On chest X-ray, the main change found was cardiomegaly, besides bronchiectasis and the presence of nodules in 71 patients $(23,9 \%)$. (Figure 1$)$.

An analysis on the use of medicines was also done. It was found that $15,2 \%$ of patients did not use any medication; of $84,8 \%$ of patients taking drugs, $32,3 \%$ used 1 to 2 drugs; $28,3 \% 3$ to $4 ; 22,5 \%$ used five or more, while $5(1,68 \%)$ patients reported using some medicine, but could not inform on data such as the number, name or dosage. (Table 2)

Finally an assessment of the release of the patient for surgery at the first visit was performed, or if the patient would need further evaluation. It was found that 233 patients $(78,5 \%)$ were released after consultation with just the anesthetist, $218(73,4 \%)$ in a single consultation and other $15(5,05 \%)$ required two consultation due to lack of complementary tests. Other 64 patients $(21,5 \%)$ required 
Table 2

Number of patients (percentage) on medications obtained from the analysis of 297 patient records

\begin{tabular}{lc}
\cline { 2 - 2 } & $\mathbf{N}(\%)$ \\
\hline Use of medication & \\
None & $45(15.2)$ \\
01 ou 02 & $96(32.3)$ \\
03 ou 04 & $84(28.3)$ \\
05 or more & $67(22.5)$ \\
Couldn't say & $05(1.7)$ \\
\hline
\end{tabular}

return to pre-anesthetic assessment clinic due to interconsultation request with other specialties for clinical control, particularly in cardiology, pulmonology, and endocrinology. Thus, 48 patients $(16.2 \%)$ were the PAA's office twice, and 33 of those went through interconsultation with experts from another area and were released in the second evaluation; other 22 patients $(7,4 \%)$ required three visits, and 4 patients $(1,3 \%)$, four consultations. These data are shown in Figure 2. Only five patients, which corresponds to $1.7 \%$, had a surgery released only with local anesthesia without the use of area blockade.

Patients with blood glucose higher or equal to $100 \mathrm{mg} \cdot \mathrm{dl}^{-1}$, which had no knowledge of the diagnosis were referred for evaluation in the basic health units.

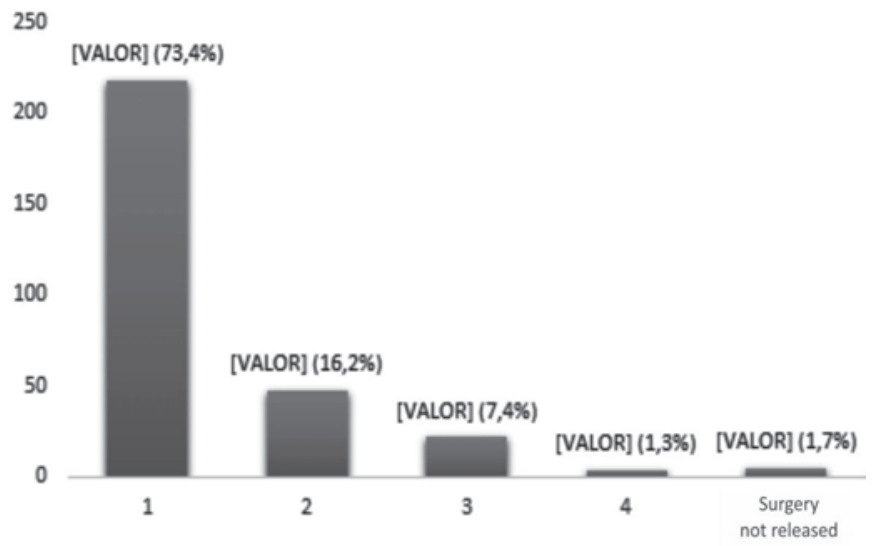

Figure 2: Number of consultations (percentage) that patients went through until being released for surgery.

\section{Discussion}

This research showed that the vast majority of patients more than sixty years old, scheduled for eye surgery, has comorbidities, especially heart disease. The data also indicated that the pre-anesthetic evaluation revealed new diagnostic possibilities and changed clinical and laboratory conditions, as hypertension ${ }^{17}$ and diabetes mellitus ${ }^{18}$.

Ophthalmologic surgeries are the most common surgeries in elderly patients, especially correction of cataract ${ }^{19-25}$. A lot of them are outpatients, with the use of local anesthesia, usually in conjunction with intravenous sedation. The perioperative morbidity and mortality rates associated with cataract surgery are low ${ }^{12,26}$. However, patients tended to be older and have significant coexisting illnesses. Thus, many surgeons believe that a systematic clinical evaluation associated with laboratory tests should be performed before a patient is considered eligible for surgery. Since a patient must undergo an elective surgery on his best clinical form, pre-anesthetic evaluation plays an important role in confirming the appropriate clinical condition of the patient for surgery. If that's not the case, refer the same to optimization diseases already known, and also diagnose or rule out other diseases, as it has been seen in this study in relation to diabetes mellitus.

Many current factors led to a diversification in the embodiment of the pre-anesthetic approach by anesthesiologists, including outpatient admissions, advances in anesthetic and surgical techniques, the age and comorbidities of patients, and costs. This caused an increase in pressure on health systems, on surgeons and anesthesiologists to evaluate and drive efficiently patients, focusing not only on safety but also in care with low $\operatorname{costs}^{27}$. The economic recession further complicates the perioperative care because patients delay or eliminate routine disease screening visits and presented for surgery with medical conditions that may delay or even cancel surgery ${ }^{3}$. Several approaches to combat these problems have been proposed, including the development of more specific guidelines for testing and consultations before anesthesia and surgery ${ }^{7,8}$, and the development of pre-operative assessment clinics that systematically assess patients and properly define the perioperative care ${ }^{28,29}$. With the continued growth of outpatients, the anesthesiologist came to have new roles, which apparently require additional skills to administer a good anesthesia. In most clinics, the goal is to solve the preoperative problems well in advance of the day of surgery, minimizing cancellations and complications $^{3}$. And this is the current evaluation model in the service of UFTM that through outpatient evaluation, refers patients to the various clinical specialties, until they are in proper physical condition to undergo surgery. There are few reliable data to classify if an adult patient is inappropriate for an ambulatory surgery. As anesthesiologists have become more experienced with the administration of ambulatory anesthesia, the list of patients considered inappropriate has decreased. It is necessary to individualize a decision for each patient so that the pre-anesthetic evaluation plays its biggest role. With few exceptions, the suitability of a case for ambulatory surgery is determined by a combination of factors, including considerations of the patient, the surgical procedure, the anesthetic technique and comfort of the anesthesiologist and the surgeon. With the assessment made in the pre-anesthesia ambulatory, we observed that many patients could not be released for surgery after a single consultation, without going through a process of evaluation by other clinics, and optimization of the clinical picture. All this becomes more important when we face the increasing number of elderly patients for ambulatory surgery. And this can be clearly seen at work in which the average age was of 71,5 years. And these older patients who are "well" are more likely to have elective surgery, both to prevent the worsening of any existing disease, as to improve their quality of life. In this context, the pre-anesthetic evaluation is especially important in the elderly to determine their physical and functional status, to improve pre-existing conditions and implement a perioperative plan that includes choosing the proper location for the surgery and proper postoperative care ${ }^{30}$.

Considering all these data, the pre-anesthetic evaluation 
became the time of the evaluation of the patient and assumed the role of primary care through clinical evaluation of patients. Besides, other items should be considered. Elderly patients often make use of multiple medications. Forty percent of them take more than five drugs per week, $12 \%$ to $19 \%$ over 10 drugs $^{31}$. Our study showed that $84,8 \%$ of the patients received at least one drug per day, and 22,5\% would take five drugs (Table 2). Proper instruction for the perioperative management of chronic medications is part of the pre-anesthetic evaluation and it is

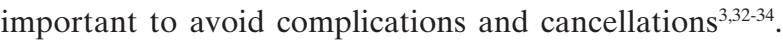

The pre-anesthetic evaluation has function to identify patients who are unfit for surgery at that moment. Patients classified as ASA 3 or 4, clinically unstable, are not considered suitable for performing an ambulatory surgery. The results of this study showed that $24,9 \%$ of patients were classified as ASA 3 and 1,34\% ASA 4, and were released to undergo the procedure after having stabilized their disease, mainly for cardiology.

The main diseases requiring perioperative control were hypertension ${ }^{17}$ and $\mathrm{DM}^{18}$. This is necessary to minimize adverse perioperative events ${ }^{35-37}$. Some specific complications of the ocular surgery as the suprachoroidal hemorrhage, although rare, can potentially lead to blindness. It can occur after cataract surgery, glaucoma, keratoplasty and vitreoretinal surgery. Some systemic risk factors normally associated with this complication are: poorly controlled hypertension, preoperative use of anticoagulant therapy, history of ischemic heart disease, the presence of respiratory diseases and $\mathrm{DM}^{38,39}$. Although it is a multifactorial complication, control of known factors involved can minimize the risks and consequences of a massive suprachoroidal hemorrhage.

In addition to the clinical evaluation, evaluation of complementary tests is part of the pre-anesthetic consultation, and is usually ordered by the surgeon. The literature has shown that for the vast majority of elderly patients with stable diseases, routine laboratory tests are a waste of time and financial resources ${ }^{1,3-5,12,14-16,40}$. In this study, about ten tests was performed per patient, and only the determination of blood glucose can be considered important for the assessment of the patients. The results showed that $25,92 \%$ of patients had blood glucose levels above $100 \mathrm{mg} \mathrm{dl} .^{-1}$, and other 5,38\% knew they had DM, but were with what is considered inadequately controlled glycemic levels (higher than $180 \mathrm{mg}$. $\mathrm{dl}^{-1}$ ). Obviously not all of these $25,92 \%$ were considered to have DM. But considering that, according to the American Diabetes Association $^{18}$, over $25 \%$ of adults over the age of 65 have diabetes, and many are not diagnosed, the investigation of these research results is needed, as well as the control of those who are not well treated in order to reduce complications, especially infections ${ }^{41,42}$. In addition to laboratory tests, electrocardiogram (ECG) is a test that is also part of the routine request of surgeons. Electrocardiographic changes were found in $34,68 \%$ of patients in this study. A study ${ }^{43}$ showed that $75,2 \%$ of patients over 75 had at least one abnormality in ECG, and the authors concluded that these abnormalities are of limited value in predicting postoperative cardiac complications. Therefore, the authors recommend performing a preoperative ECG mainly for comparative purposes, in case it's necessary to carry out another exame ${ }^{43}$. Recently, Philips ${ }^{44}$ in an ambulatory center in
Florida, USA, in which the medical pre-anesthetic evaluation is necessary for the realization of ophthalmologic surgery, draw the conclusion that the pre-anesthetic consultation for these surgeries is able to identify new diagnostics or unstable medical conditions. The study comprised 530 patients and $40 \%$ of them were identified as new or unstable medical conditions. Consistent with previous works ${ }^{12}$ on the effectiveness of many preoperative tests, it also showed that the performance of preoperative tests does not prevent the occurrence of events in perioperative patients undergoing ambulatory surgery for cataract correction.

Although these results have no significant impact on the perioperative period ${ }^{5,14}$, many are very important for the long-term overall health of the patient, often playing a role of primary care. The pre-anesthetic evaluation may provide an opportunity to trace diseases such as diabetes mellitus and thereby initiate treatment early, although there was no impact on the outcome perioperative ${ }^{16}$.

Although this study has several limitations, such as being a retrospective study and with a relatively small sample, it may be able to demonstrate that the anesthesiologist can have a attitude more focused on "discoveries" that are relevant to a surgical risk immediately. Also in relation to diseases already diagnosed, but inadequately controlled, especially in relation to those of high social impact such as hypertension and diabetes.

We conclude that the pre-anesthetic evaluation for ophthalmic surgery, performed at a public ambulatory unit, contributes to the improvement of the general health of patients through the possibility of new diagnostic and clinical improvement of poorly controlled disease. Allowing surgery on its best clinical condition and playing a role in the overall health of patients, which goes beyond the immediate perioperative period, being, therefore, considered necessary in the elderly population using the public service.

\section{RefEReNCES}

1. Lira RP, Nascimento MA, Kara-José N, Ariera CE. Valor preditivo de exames pré-operatórios em facectomias. Rev Saúde Pública. 2003;37(2):197-202.

2. Bisinotto FM, Pedrini Jr M, Alves AL, Andrade, MA. Implantação do serviço de avaliação pré-anestésica em Hospital Universitário. Dificuldades e resultados. Rev Bras Anestesiol. 2007; 57(2):167-76.

3. Lira RP, Nascimento MA, Temporini ER, Kara-José N, Arieta, EL. Suspensão de cirurgia de catarata e suas causas. Rev Saúde Pública. 2001;35(5):487-9.

4. Lira RP, Covolo GA, Monsanto AR, Kara-José N, Arieta CE. Influence of preoperative testing on cancellation of ambulatory cataract surgery in adults. Ann Ophthalmol. 2002;34(3):203-5.

5. Lira RC, Nascimento MA, Morerira Filho DC, Kara-José N, Arieta EL. Are routine preoperative medical tests needed with cataract surgery? Rev Panam Salud Publica. 2001; 10(1):13-7.

6. Mathis MR, Naughton NN, Shanks AM, Freundlich RE, Pannucci CJ, Chu Y, Haus J, Morris M, Kheterpal S. Patient selection for day case-eligible surgery: identifying those at high risk for major complications. Anesthesiology. 2013;119(6):1310-21.

7. Committee on Standards and Practice Parameters, Apfelbaum JL, Connis RT, Nickinovich DG; American Society of Anesthesiologists Task Force on Preanesthesia Evaluation, Pasternak LR, Arens JF, Caplan RA, Connis RT, Fleisher LA, Flowerdew R, Gold BS, 
Mayhew JF, Nickinovich DG, Rice LJ, Roizen MF, Twersky RS. Practice advisory for preanesthesia evaluation: an updated report by the American Society of Anesthesiologists Task Force on Preanesthesia Evaluation. Anesthesiology. 2012;116(3):522-38.

8. Fleisher LA, Beckman JA, Brown KA. American College of Cardiology Foundation/American Heart Association Task Force on Practice Guidelines, American Society of Echocardiography, American Society of Nuclear Cardiology, Heart Rhythm Society, Society of Cardiovascular Anesthesiologists, Society for Cardiovascular Angiography and Interventions, Society for Vascular Medicine, Society for Vascular Surgery: 2009 ACCF/AHA focused update on perioperative beta blockade incorporated into the ACC/AHA 2007 guidelines on perioperative cardiovascular evaluation and care for noncardiac surgery. J Am Coll Cardiol. 2009; 54(22):e13-e118.

9. Thilen S, Treggiari M, Weaver E. An Opportunity for anesthesiologists to add value by controlling preoperative resources [abstract]. Presentation at ASA Practice Management Meeting; Orlando, FL. January 27, 2012. PM21.

10. Gupta A. Preoperative screening and risk assessment in the ambulatory surgery patient. Curr Opin Anaesthesiol. 2009;22(6):705-11.

11. Bryson GL, Chung F, Finegan BA, Friedman Z, Miller DR, Vlymen J, et al. Canadian ambulatory Anesthesia Research and Education group. Patient selection in ambulatory anesthesia - an evidencebased review: part I. Can J Anaesth. 2004;51(8):768-81. Review.

12. Bryson GL, Chung F, Cox RG, Crowe MJ, Fuller J, Henderson C, et al. Patient selection in ambulatory anesthesia - An evidence-based review: Part II. Can J Anaesth, 2004;51(8):782-94. Review.

13. Schein OD, Katz J, Bass EB, Tielsch JM, Lubomski LH, Feldman MA, et al. Study of Medical Testing for Cataract Surgery. The value of routine preoperative medical testing before cataract surgery. N Engl J Med, 2000;342(3):168-75.

14. Arieta CE, Nascimento MA, Lira RP, Kara-José, N. Desperdício de exames complementares na avaliação pré-operatória em cirurgias de catarata. Cadern Saúde Pública. 2004; 20(1):303-10.

15. Tallo, FS, Soriano ES, Alvarenga LS. Avaliação pré-operatória na cirurgia de catarata. Arq Bras Oftalmol. 2007;70(4):633-7.

16. Nascimento MA, Lira RP, Kara-José N, Arieta CE. Valor preditivo da glicemia de jejum pré-operatória de pacientes diabéticos quanto ao resultado cirúrgico da cirurgia de catarata. Arq Bras Oftalmol. 2005;68(2):213-7.

17. Rosendorff C, Black HR, Cannon CP, Gersh BJ, Gore J, Izzo JL, et al. Treatment of hypertension in the prevention and management of ischemic heart disease: A scientific statement from the American Heart Association Council for High Blood Pressure Research and the Councils on Clinical Cardiology and Epidemiology and Prevention. Circulation.2007; 115(21):2761-88.

18. American Diabetes Association: Standards of Medical Care in Diabetes-2012. Diabetes Care. 2012; 35 Suppl. 1:s11-s6.

19. Desai P, Reidy A, Minassian DC. Profile of patients presenting for cataract surgery in the UK: national data collection. Br J Ophthalmol. 1999; 83(8):893-6.

20. McKibbin M. The pre-operative assessment and investigation of ophthalmic patients. Eye (Lond). 1996;10(1):138-40.

21. Bryson GL, Wyand A, Bragg PR. Preoperative testing is inconsistent with published guidelines and rarely changes management. Can J Anaesth. 2006; 53(3):236-41.

22. Richman DC. Ambulatory surgery: How much testing do we need? Anesthesiol Clin, 2010; 28(2):185-97.
23. Cullen KA, Hall MJ, Golosinskiy A. Ambulatory surgery in the United States, 2006. Natl Health Stat Report. 2009; (11):1-25.

24. Thilen SR, Bryson CL, Reid RJ, Wijeysundera DN, Weaver EM, Treggiari MM. Patterns of preoperative consultation and surgical specialty in an integrated healthcare system. Anesthesiology. 2013;118(5):1028-37.

25. Thilen SR, Treggiari MM, Lange JM, Lowy E, Weaver EM, Wijeysundera DN. Preoperative consultations for medicare patients undergoing cataract surgery. JAMA Intern Med, 2014;174(3):380-8.

26. Keay L, Lindsley K, Tielsch J, Katz J, Schein O. Routine preoperative medical testing for cataract surgery. Cochrane Database Syst Rev. 2012; 3:CD007293.

27. Newman MF, Mathew JP, Aronson S. The evolution of anesthesiology and perioperative medicine. Anesthesiology. 2013;118(5):1005-7.

28. Harnett MJ, Correll DJ, Hurwitz S, Bader AM, Hepner DL. Improving efficiency and patient satisfaction in a tertiary teaching hospital preoperative clinic. Anesthesiology. 2010;112(1):66-72.

29. Correll DJ, Bader AM, Hull MW, Hsu C, Tsen LC, Hepner DL. Value of preoperative clinic visits in identifying issues with potential impact on operating room efficiency. Anesthesiology. 2006; 105(6):1254-9.

30. Oresanya LB, Lyons WL, Finlayson E. Preoperative assessment of the older patient: a narrative review. JAMA. 2014; 311(20):2110-20.

31. Barnett SR. Polypharmacy and perioperative medications in the elderly. Anesthesiol Clin. 2009;27(3):377-89.

32. Deiner S, Silverstein JH. Anesthesia for geriatric patients. Minerva Anestesiol. 2011,77(2):180-9.

33. Smith J, Jackson I. Beta-blockers, calcium channel blockers, angiotensin converting enzyme inhibitors and angiotensin receptor blockers: should they be stopped or not before ambulatory anaesthesia? Curr Anaesthesiol. 2010;23(6):687-90.

34. Lermitte J, Chung F. Patient selection in ambulatory surgery. Curr Opin Anaesthesiol. 2005;18:598-602.

35. Gupta A. Strategies for outpatient anaesthesia. Best Pract Res Clin Anaesthesiol. 2004:18(4):675-92.

36. Shnaider I, Chung F. Outcomes in day surgery. Curr Opin Anesth, 2006; 19:622-629.

37. Aurinia L, White PF. Anesthesia for the elderly outpatient. Curr Opin Anesth. 2014;27(6):563-75.

38. Obuchowska I, Mariak Z. Risk factors of massive suprachoroidal hemorrhage during extracapsular cataract extraction surgery. Eur J Ophthalmol. 2005;15(6):712-7.

39. Jeganathan VS, Ghosh S, Ruddle JB, Gupta V, Coote MA, Crowston JG. Risk factors for delayed suprachoroidal haemorrhage following glaucoma surgery. Br J Ophthalmol. 2008;92(10):1393-6.

40. Shalwala A, Hwang RY, Tabing A, Sternberg P, Kim SJ. The value of preoperative medical testing for vitreoretinal surgery. Retina. 2015;35(2):319-25.

41. Imasogie N, Wong DT, Luk K, Chung F. Elimination of routine testing in patients undergoing cataract surgery allows substantial savings in laboratory costs. A brief report. Can J Anaesth. 2003; 50(3):246-8.

42. Ata A, Lee J, Bestle SL, Desemone J, Stain SC. Postoperative hyperglycemia and surgical site infection in general surgery patients. Arch Surg. 2010; 145(9):858-64. 
43. Liu LL, Dzankic S, Leung J.M. Preoperative electrocardiogram abnormalities do not predict postoperative cardiac complications in geriatric surgical patients. J Am Geriatr Soc, 2002;50(7):1186-91.

44. Phillips MB, Bendel RE, Crook JE, Diehl NN. Global health implications of preanesthesia medical examination for ophthalmic surgery. Anesthesiology, 2013; 118(5):1038-45.

\section{Corresponding author:}

Profa. Dra. Flora Margarida Barra Bisinotto

Av. Frei Paulino, 30Hospital de Clínicas - UFTM - Disciplina de AnestesiologiaBairro Abadia, Uberaba, Minas Gerais.

ZIP Code 38025-180

E-mail: flora@mednet.com.br 